\section{DENTAL SHOWCASE TO HIT LONDON}

The UK's biggest dental exhibition, the British Dental Trade Association (BDTA) Dental Showcase, will be in full swing at ExCeL London from 4-6 October. Over 300 exhibitors and 10,000 members of the dental team are expected to attend.

Delegates will enjoy a real voyage of discovery this year, with a wide variety of companies from the UK and abroad displaying the latest dental products and services.

Saturday 6 October will feature the 'Tech Zone' An informal area for technicians and laboratory owners, the Tech Zone will be situated centrally within the main hall, including a series of 'bitesized' presentations by leading technicians, a lounge area to mix, mingle and meet clients and the opportunity to gain verifiable CPD.

Visitors can gain general CPD hours from walking around the show interacting with exhibitors. Further CPD opportunities include complimentary mini-lectures sponsored by Oral-B and a live surgery sponsored by Henry Schein, as well as a Business Clinic covering a wide range of current, relevant topics. The official Show Guide will also contain three hours of verifiable CPD for all delegates.

Whether you want to broaden your knowledge, keep up to date on developments in dental technology, or shop for new equipment and materials for your practice, the BDTA Dental Showcase 2012 is not to be missed - whatever your role in the dental team.

Visit www.dentalshowcase. com to register for a free ticket.

\title{
DENTIST INVENTS NEW ORAL HEALTH SYSTEM
}

On 27 June 2012 Dr Hani Mostafa, a dentist from Leamington Spa, officially launched his own invention, the oral health system called Gumsaver, at the Design Museum in London.

The Gumsaver system includes a soft bristled tool specifically designed to remove bacteria from beneath the gum line, and a three-step cleaning technique designed to make the task of looking after gums and teeth simple for dental professionals and patients.

One of Dr Mostafa's patients, who tried in vain to ward off her periodontal disease and receding gums over many years by every method she and her dentist and hygienist could think of, gave candid testimony to the effectiveness of Gumsaver. Within days of use, profuse bleeding from the patient's gums upon using the Gumsaver had ceased and her tooth mobility reduced.

The ergonomic design of the Gumsaver brush and the simple three-step technique mean that patients can be taught how to treat and prevent periodontal disease at home. The bristle heads are angled towards each other and are spaced apart, providing a small clearance in which the interdental spaces are lined up during use. An up and down motion will guide a head of the Gumsaver under the gumline and into the pocket to remove deep-seated bacteria.

An instructional video and more information can be found at www.gumsaver.co.uk.

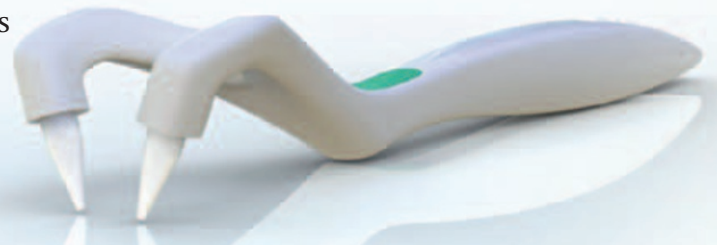

\section{VULNERABLE PATIENTS PROGRAMME LAUNCHED}

Smile-on in conjunction with the Kent, Surrey and Sussex (KSS) Deanery have developed an interactive

learning

programme

which aims

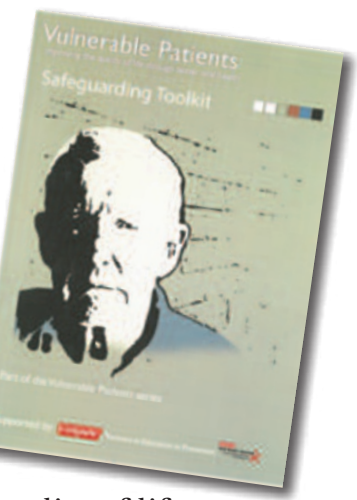

to improve the quality of life of vulnerable adult and child patients. The programme addresses the role of dental and other healthcare professionals and carers in safeguarding vulnerable patients' welfare and improving their oral health - addressing the Care Quality Commission's policies on safeguarding vulnerable adults.

Vulnerable patients: adults has been released and part two, Vulnerable patients: children will be released later in 2012 .

The first part of the programme, which includes verifiable CPD, looks at five specific groups of vulnerable adult patients. As users progress through the interactive programme, video clips feature actors performing typical scenarios that might be encountered by healthcare professionals, such as a dentist visiting 'Bill', an elderly patient with denture problems for whom issues arise over informed consent.

The programme can be purchased online for $£ 99$.

www.healthcare-learning.com/ elearning

\section{A BRITISH LASER FOR AUSTERE TIMES}

QuickLase have launched the dentaLase Laser, a new 'recession free' laser. It is Britishmade, calibrated and serviced in the UK and is designed to appeal to and be obtainable by all dental practices without fear of paying over the top. It comes loaded with full features and eight programmable presets, including troughing, gum recontouring, perio, endo and tooth whitening. There is a colour coded screen for ease of use and a built in fibre caddy to protect the fibre.
In addition there is a wall mounted bracket option.

The dentaLase Laser is half the price of its competitors. QuickWhite have also launched new offers for carbamide and new-look in-surgery kits.

For more information call 01227780009 or visit www. Quicklase.com.

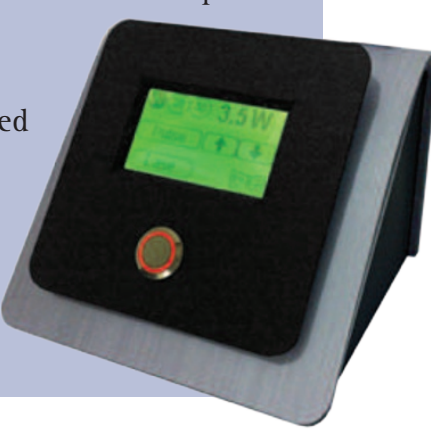

